\title{
High PATI Score is Associated with Increase Mortality in Patients with Penetrating Abdominal Injuries; A Retrospective Review
}

\author{
Syed Zohaib Gulzar Naqvi ${ }^{1, *}$, Shahrukh Effandi ${ }^{2}$ and Hasnain Zafar $^{3}$ \\ ${ }^{1}$ Department of General Surgery, Aga Khan University and Hospital, Karachi, Pakistan. \\ ${ }^{2}$ Hepatobiliary Surgery, Aga Khan University and Hospital, Karachi, Pakistan. \\ ${ }^{3}$ Associate Department of General, Surgery Department, Aga Khan University and Hospital, Karachi, Pakistan.
}

\begin{abstract}
Background: Worldwide, injuries due to violence constitute eighth leading cause of death. Penetrating abdominal injuries account for third most common area involved. In literature PATI has been utilized to estimate the severity of abdominal trauma, decision making regarding repairing the damage and even risk of post-operative complications. We aimed and intended to use PATI score (penetrating abdominal trauma index) as a more accurate method of quantifying the extent of damage in patients with the penetrating abdominal trauma and association of high PATI score (>25) with mortality.
\end{abstract}

Objective: To determine the association of mortality in patient with penetrating abdominal trauma with high PATI score (more than 25).

\begin{abstract}
Methods and Design: Medical records of all adult patients (age more than 16 years of age) admitted at Aga Khan University and Hospital with penetrating abdominal injuries from 2006 - 2012 were reviewed retrospectively; adult patients with complete medical records were included and patients with missing data were excluded from the study. SPSS version 19 was used for data entering and statistical analysis.

Results: We included 74 patients, mostly men (95.9\%), with a mean age of $34.4+/-11.9$ years. Gunshot injuries accounted in 63 patients. Majority of the patients (31.1\%) presented with grade 2 shock. Emergency laparotomies were done in 62 patients, 4 patients underwent damage control laparotomies. Seven patients were treated conservatively. Most commonly injured intraabdominal organ was small bowel (31\%). Mean injury severity score was 12.97, mean revised trauma score was 7.63, and mean TRISS was 96.19. Mean PATI Score was 10.85 +/- 8.9. Mortality occurred in 9 patients, among them four patient had PATI score more than 25 ( $\mathrm{p}=0.021$ ). There is a seven time increase in risk of mortality in patients with high PATI score.

Conclusion: Gunshots are mainly responsible for penetrating abdominal injuries in our study. Management was by mandatory laparotomy after clinical assessment, in majority of patients. PATI score is a valuable scoring for estimation of severity of penetrating abdominal injury in context with the outcome.
\end{abstract}

Keywords: Penetrating abdominal index score (PATI), injury severity score (ISS), trauma and injury severity score (TRISS). doi.org/10.21089/njhs. 11.0030

\section{INTRODUCTION}

Violence is a public health problem, especially in low and middle income countries, constituting 8th leading cause of death in the world, current data showing that the problem is on the increase [1, 4]. Karachi, being the most populated city of the country and because of its important geographical location, it bears most influential economic status for the country. On the other side because of strong political influences this city has been a major victim of street violence and bomb blasts. Penetrating wounds represent $25 \%$ of all

*Address correspondence to this author at the Department of General Surgical, Aga Khan University and Hospital, Karachi, Pakistan.

E-mail: zohaib.naqvi1@gmail.com urban traumas. Abdomen is the third most common injured region of the body, involving $20 \%$ of all injured civilians who undergo surgical intervention [2]. Several scoring systems have been used in the literature for estimation of abdominal trauma injuries. We intended to use PATI score, the Penetrating Abdominal Trauma Index (PATI) which was introduced in 1981 by Moore et al. P, described as a useful tool for injury assessment, the risk of developing complications and served as a tool in the decision-making in managing penetrating abdominal trauma [1, 10, 12].

\section{METHODS AND DESIGN}

Medical records of all adult patients (age more than 16 years of age) admitted at Aga Khan University and Hospital with 
penetrating abdominal injuries from 2006 - 2012 were reviewed retrospectively; adult patients with complete medical records were included and patients with missing data were excluded from the study. SPSS version 19 was used for data entering and Statistical analysis.

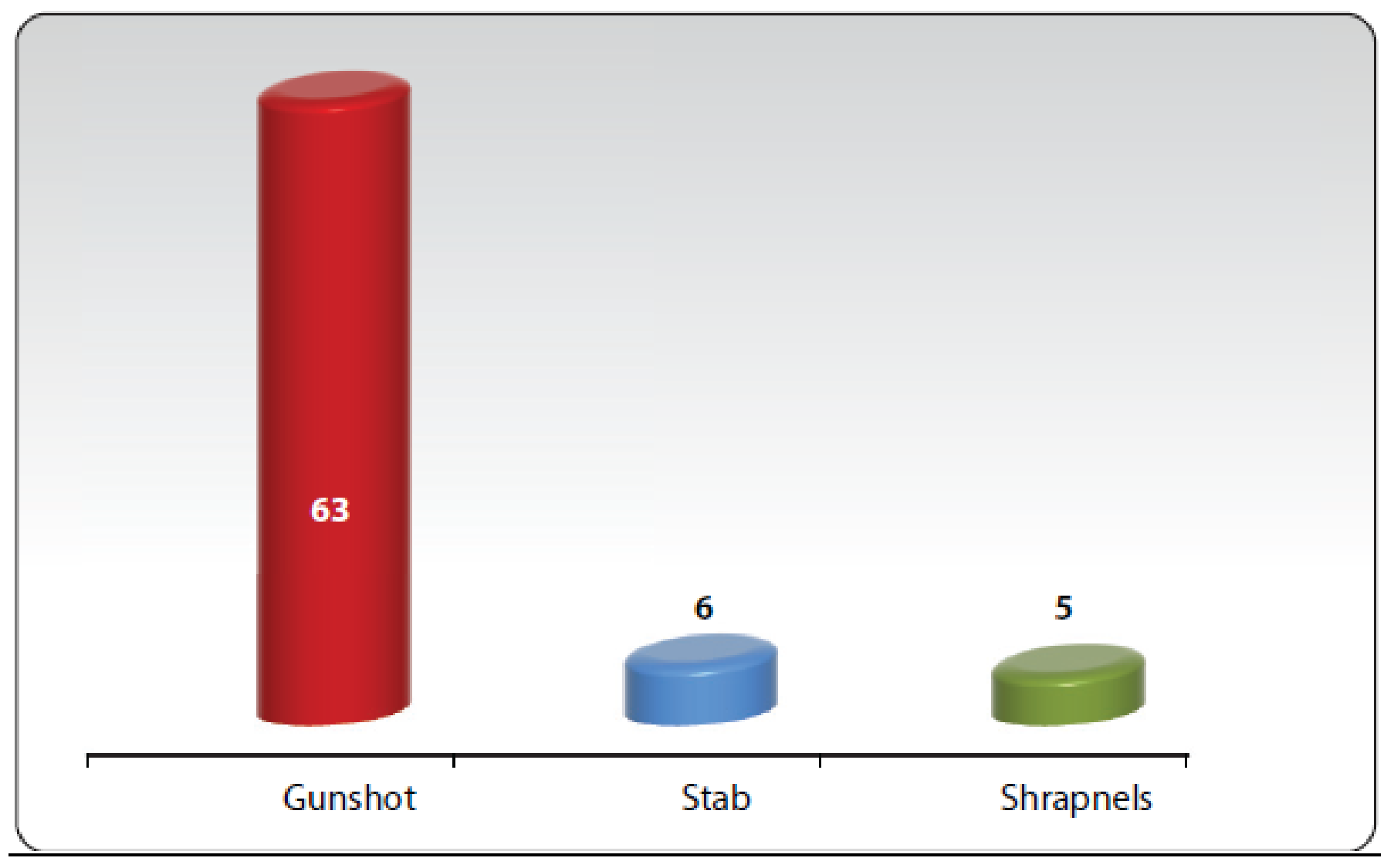

Fig. (1). Showing distribution of patients as per mode of injury.

\section{RESULTS}

We identified total of 74 patients, mostly men (95.9\%), with a mean age of $34.4+/-11.9$ years who presented with penetrating abdominal trauma. Among them gunshot injuries accounted for 63 patients (85.1\%), stab wounds accounted for 6 patients (8.1\%) and in 5 patients (6.8\%) shrapnel were the reason for their penetrating injury (Fig. 1).

About 41 patients were transferred from the primary site and 33 were referred from other hospitals. Most of the patients (31.1\%) presented with grade 2 shock (Fig. 2). Mean time of presentation from site of injury to hospital was 90 minutes, and mean time of intervention (duration from time of presentation to surgery) was 60 minutes. Emergency laparotomies were done in 62 patients, 4 patients underwent damage control laparotomies.7 patients were treated conservatively. Most commonly injured organ was small bowel (31\%) followed by large bowel (29.8.), stomach (21.7\%), liver (12.2\%) and spleen (10.9\%). Mean injury severity score was 12.97, mean revised trauma score was 7.63, and mean TRISS was 96.19. Mean PATI Score was $10.85+/$ - 8.9. Seven patients had PATI score more than 25 , among them 4 died $(\mathrm{p}=0.02)$ (Table 1). Overall mortality occurred in 9 patients (12.2\%), six mortalities occurred on DAY1 secondary to hypovolemic shock, one mortality was on DAY 3 cause of death was MODS, and two patients died on DAY 16, DAY 37 secondary to sepsis, following trimodial pattern of death. High PATI score $(>25)$ is associated with 7 times increased risk of mortality ( $\mathrm{CI}=$ 1.380 to 3.719 ).

\section{DISCUSSION}

Violence is particularly concentrated among adolescents and young adults and has become the leading cause of potential 


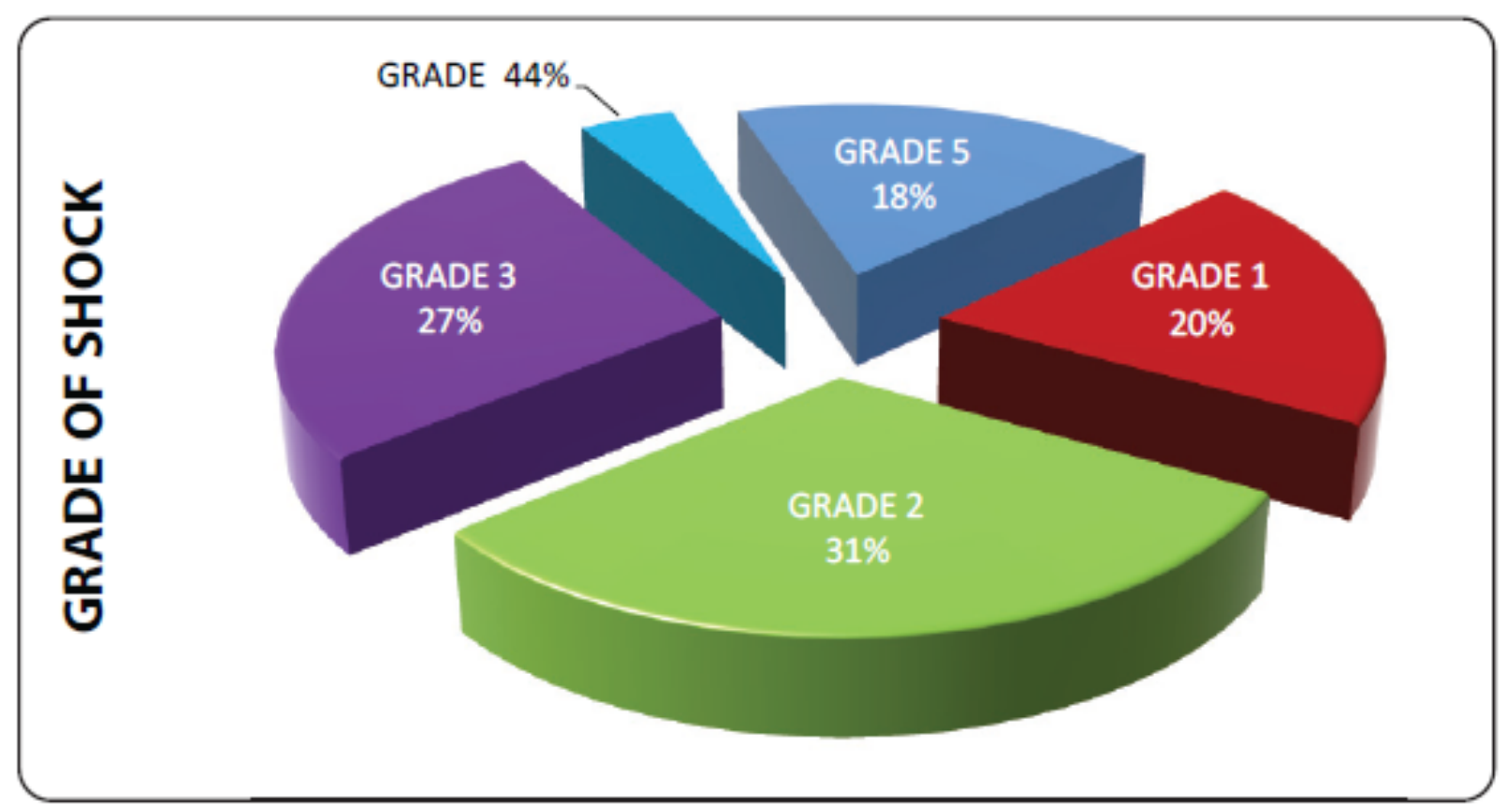

Fig. (2). Showing grade of shocks.

Table (1). Showing statical significance between PATI score and mortality along with the cause of death.

\begin{tabular}{|c|c|c|c|c|c|c|c|c|}
\hline & \multicolumn{6}{|c|}{ mortality } & \multirow[b]{2}{*}{ Total } & \multirow[b]{2}{*}{ p-value } \\
\hline & no mortality & sepsis & ARF & $\begin{array}{c}\text { cardiac } \\
\text { arythmias }\end{array}$ & ARDS & hemrrohage & & \\
\hline PATI RANGE & 8 & $\overline{0}$ & 0 & 0 & $\overline{0}$ & 1 & 9 & \\
\hline $1-9$ & 33 & 0 & 1 & 0 & 0 & 0 & 34 & \\
\hline $10-15$ & 8 & 1 & 0 & 0 & 0 & 0 & 9 & \\
\hline $16-20$ & 12 & 0 & 0 & 0 & 0 & 1 & 13 & 0.021 \\
\hline $21-24$ & 1 & 0 & 0 & 0 & 0 & 1 & 2 & \\
\hline$>25$ & 3 & 1 & 0 & 1 & 1 & 1 & 7 & \\
\hline Total & 65 & 2 & 1 & 1 & 1 & 4 & 74 & \\
\hline
\end{tabular}

years of life lost in most countries [3]. According to CPLC records, there has been an increase in number of killing over past few years in Karachi especially in 2010 where about 1339 people lost their life on the account of terrorism [5]. Across the world the frequency of penetrating abdominal trauma (PAT) varies because it relates to the weapons available, industrialization and the presence of military conflicts [6]. These injuries can be caused by gunshot, sharp object like knives, metal object, and shrapnel etc., but in our region gunshot is the most common cause of penetrating abdominal injuries. We focused on patients with abdominal injuries, most of them were male constituting about 95.9\%, similar to a study by Muazzam Nasrullah [7]. About 31\% of patients $(n=23)$ were in grade 2 shock as shown in Fig. (2).
Clarke et al. [8] showed 98\% of positive laparotomy in 192 patients. In current study $64 \%$ of patients were rushed to OR either because of significant injuries, hemodynamically unstability or ground realities based decision by trauma team, four had damage control laparotomy. Most common hollow abdominal viscera involved was small bowel 31\% $(n=23)$ followed by Large bowel $29.8 \%(n=22)$ and then stomach $21.7 \%(\mathrm{n}=16)$. And most common solid visceral involvement was Liver $12.2 \%(n=9)$ followed by Spleen $10.9 \%(n=8)$. For small bowel injuries primary resection and anastomosis was the treatment of choice with no postoperative leakage. For large bowel exteriorization was mostly done, all the stomach perforations were repaired primarily without any post-operative complications. Eight 
patients with gunshot were successfully managed conservatively. They did not seek surgical intervention because of being hemodynamically stable, absence of signs of peritonitis/peritonism, unconvincing trajectory of the bullet inconcordence with no injury detection on FAST and CT SCAN abdomen. As enhanced abdominal-pelvic CT can accurately exclude violation of peritoneum, thus avoiding unnecessary surgical intervention in majority of patients without definite need for laparotomy [9]. Trauma scoring systems were used to quantify the severity of an injury, estimate the probability of survival, facilitate pre-hospital triage, hence to organize and improve patient care [10]. Mean Penetrating Abdominal Index Score (PATI) was 10.85 $+/$ - 8.9. Overall mortality occurred in 9 patients, among them four patient had PATI score more than 25. PATI score is comparable with the mortality $(p=0.021)$ as in Table 1 .

Study by José Francisco G-L [11] showed overall risk of mortality up to 1.8 times with high PATI score, but in current study we found up to 7 times increase in mortality with high PATI score. Moore EE et al. in his study showed $50 \%$ increase in complications with high PATI score [12]. Overall mortality occurred in 9 patients (12.2\%) following the trimodial pattern of death [13-15].

\section{CONCLUSION}

Gunshots are the main cause of penetrating abdominal injury in our part of the world. Penetrating abdominal trauma index score (PATI) is a valuable scoring tool for severity estimation of penetrating abdominal injuries and there outcome.

\section{ACKNOWLEDGEMENT}

I would like to express my gratitude towards my colleagues, seniors and attendings for their kind attention, efforts and cooperation in completing this project have taken efforts in this project. It would not been possible without the support and help of individuals directly or indirectly associated with the research.

\section{CONFLICT OF INTEREST}

Declared none.

\section{REFERENCES}

[1] Murray CJ, Lopez AD. Mortality by cause for eight regions of the world: Global Burden of Disease Study. Lancet 1997; 349:1269-76.

[2] Cavina E, Neidhart JP. The trauma of the abdomen: European course of trauma care. [Last accessed on 2010 Aug 12].

[3] Neill PA, Kirton OC, Dresner LS, Tortella B, Kestner MM. Analysis of 162 colon injuries in patients with penetrating abdominal trauma: Concomitant stomach injury results in a higher rate of infection. J. Trauma., 2004; 56:304-12.

[4] Agudelo SF. Violence and health: preliminary elements for thought and action. Int. J. Health Serv., 1992; 22:365-76.

[5] CPLC, PAKISTAN

[6] T S Richmond, R Cheney, C W Schwab. The global burden of nonconflict related firearm mortality. Inj. Prev., 2005; 11:348-352.

[7] Muazzam Nasrullah, Junaid A Razzak, Firearm Injuries Presenting to a Tertiary Care Hospital of Karachi, Pakistan. J. Inj. Violence., 2009; 1(1): 27-31.

[8] Clarke DL, Allorto NL, Thomson SR. An audit of failed nonoperative management of abdominal stab wounds. Injury. 2010; 41(5): 488-91.

[9] Velmahos, G.C., Constantinou C, Tillou A, et al. Abdominal computed tomographic scan for patients with gunshot wounds to the abdomen selected for nonoperative management. J. Trauma., 2005; 59: 1155-61.

[10] Trauma.org

[11] José Francisco G-L. Penetrating abdominal trauma index: Sensitivity and specificity for morbidity and mortality by ROC analysis. Indian J. Surg., 2004; 66(6): 347-51.

[12] Moore EE, Dunn EL, Moore JB, Thompson JS.Penetrating abdominal trauma index. J. Trauma., 1981; 21(6): 439-45.

[13] M. Aldemir, I. Taçyıldız, S. Girgin, Predicting Factors for Mortality in the Penetrating Abdominal Trauma, Department of Genera Surgery, Dicle University, Faculty of Medicine, Turkey. Acta Chir Belg, 2004, 104, 429-434.

[14] Trunkey DD. Trauma. Sci Am., 1983; 249: 28-35. [PubMed]

[15] Justin Sobrino, Shahid Shafi. Timing and causes of death after injuries Proc (Bayl. Univ. Med. Cent.). 2013; 26(2): 120123.PMCID: PMC3603725. 